The Geneva Papers on Risk and Insurance, 17 (No. 64, July 1992), 343-354

\title{
Taking Aim at Environmental Risks : Questions of Feasibility and Desirability
}

\author{
by Adam M. Finkel*
}

\section{Introduction}

For the fourth time in the past quarter-century, the U.S. stands at a crossroads and must choose how best to protect human health and natural ecosystems from environmental pollution. At the three previous junctures - exemplified by the crusade to remove sewage from our waterways and smog from our cities (c. 1970), the shift to combatting the less visible health threats posed by carcinogenic substances and toxic wastes (c. 1978), and the heightening of global ecological awareness (c. 1987) - individuals and groups stepped forward to bring intellectual substance, political firepower, and institutional capabilities to bear on the newly-identified tasks.

Now, the U.S. Environmental Protection Agency (EPA) and its supporters elsewhere in the Executive Branch and in Congress have set the wheels in motion to usher in a possible fourth phase in environmental protection - the era of environmental triage. Proceeding from the twin assumptions that our financial resources can no longer expand to fulfill the growing expectations of the citizenry, and that the political process is incapable of identifying a rational means for disbursing our limited resources, these forces are turning to science - specifically to risk assessment - to revamp the national environmental agenda. Triage is "a system of priorities designed to maximize the number of survivors". If by putting more resources into the "worst risks first", EPA can provide more protection of human health and the global environment, then triage is an idea whose time has come. Yet at this juncture, it is unclear whether the momentum for change is outpacing the case for, and the political palatability of, the new vision. Through a coordinated series of research and outreach activities over the next three years, the Center for Risk Management at Resources for the Future will help broaden and focus the national debates over whether it is time to codify our environmental priorities, what our priorities should be, and by what process they should be set.

\footnotetext{
* Fellow, Center for Risk Management, Resources for the Future, Washington, DC, USA.
} 


\section{Background}

About three years ago, EPA and the Office of Management and Budget (OMB) began searching for ways to articulate a vision for an environmental protection system that was mindful of the potential limits to resources and that tried to allocate those resources in line with some objective measures of importance rather than via the "ready, fire, aim" approach (EPA Administrator William Reilly's characterization of the first 20 years of EPA's history). Since that time, the momentum in favor of "rational" environmental priority-setting has continued to grow, even as EPA, OMB, Congress, and independent groups have begun to sketch out different visions for the future. EPA is now committed to a "strategic revolution" in its budget process and organizational culture, using as its rallying point the four-volume study "Reducing Risk: Setting Priorities and Strategies for Environmental Protection" released by EPA's Science Advisory Board (SAB) in September 1990. One of the report's major conclusions was that the general public often fixates on problems that are not as serious as other problems it tends to downplay or ignore. As seen in Table 1, there are some striking differences between the SAB's list of the most dire health and ecological risks and the set of risks rated most severe in public opinion polling.

More recently, EPA's Office of Policy, Planning, and Evaluation (OPPE) began readying EPA's program offices for the full-scale implementation of an agency-wide "strategic plan". Under this plan, during the next several years each program office (in Washington and in each of the 10 regional offices) would have to specify the risk reduction goals it intends to achieve with the budgetary authority it requests. The programs would have to specify "environmental indicators" that will enable OPPE to monitor their progress, rather than justifying their budgets with reference to previous years' spending or to bureaucratic indicators such as the number of permits written or enforcement actions initiated. The other name used for the strategic planning concept is the "risk-based budget", connoting the new EPA leadership's desire to gradually reorient Agency spending in a more rational vein. Administrator Reilly has now testified before Congress on several occasions that the extent to which EPA can follow the SAB's advice to allocate resources on the basis of risk and risk reduction "will determine how 'green' the next decades will be".

The risk-based budget plan received an unexpected boost early in 1991, when President Bush released the FY' 92 budget. Among the narratives describing new themes in the Administration's approach to budgeting and regulation was a short treatise on " $\mathrm{Re}$ forming Regulation and Managing Risk Reduction Sensibly". This narrative advanced the proposition that "society's resources for reducing risk are being poorly allocated", on the basis of OMB calculations (see Table 2) of the "cost per life saved" (CPLS) of some 50 federal health and safety regulations. OMB apparently believes that risks (of diverse kinds) should be ranked in ascending order of the CPLS associated with their control, and that agency and private-sector resources should flow towards interventions that save lives at the least cost. OMB acknowledges that individual citizens perceive risks according to factors other than cost-effectiveness, but highlights only one such factor - the presence or absence of trust in "America's private and public institutions", - implying that it is those citizens who lack such trust who want to force government to regulate many risks regardless of the CPLS of control.

Along with this more theoretical discussion, the section on risk reduction unveiled a new OMB initiative, wherein various federal agencies will be required to help OMB 
analyze 11 of their programs with an eye towards "risk management budgeting". This initiative will cover seven major regulatory programs (including EPA's "corrective action" requirements at active hazardous waste disposal facilities and OSHA's cadmium standard) and four non-regulatory programs (e.g., abandoned waste-site cleanups at the Departments of Defense and Energy). According to OMB, the FY '93 U.S.Budget will reflect the results of cost-effectiveness analyses of these 11 programs. $^{1}$

There are many factors mitigating in favor of the federal government taking a careful look at how much it is spending (directly and indirectly) to control environmental health and safety risks, and at how the limited resources available for these purposes are allocated among a host of competing programs. The former issue (the "size of the pie") is made ever more compelling by the national concern over the budget deficit (which affects the evaluation of direct federal spending) and over international competitiveness (as affected by corporate spending required by regulation). Moreover, the "conventional wisdom" stresses the notion that environmental protection has reached a point of diminishing returns, since we have already reduced or eliminated many of the most visible and damaging sources of pollution (e.g., untreated sewage, lead in gasoline). The implication of this is that now, an increased national risk reduction effort aimed at potentially marginal problems might represent "overkill". On the other hand, various factors - the continued emphasis on a particularly dreaded health endpoint (cancer), the generally rising expectations for personal health and for social equity in the distribution of costs and benefits, and the discovery of new sources of risk and of more subtle health effects - all tend to bolster the widely-held view that continued or even redoubled efforts are necessary. Although major U.S. social programs typically exhibit a large amount of budgetary inertia, the recent move to reevaluate the size of the defense budget and the decision to spend many thousands of millions to "bail out" failed savings institutions both suggest that there can be a tangible connection between a national assessment of need and the aggregate social effort expended. One goal of our research and outreach activities will be to help inform the debate over whether the total national risk reduction effort is out of proportion (in either direction) to the magnitude of the problems the nation is trying to address.

The debate over allocation is even more contentious, as it pits proponents of specific environmental programs against each other, even as it unites those concerned with particular kinds of risk against those arguing that more progress could be made if we reallocated money across broad categories. For example, while officials within EPA's Office of Air and Radiation might argue over whether lung cancer incidence could be more effectively reduced by controlling indoor radon or by controlling coke oven emissions, they might well agree that the Agency should not have to transfer part of its budget to fund smoking-cessation programs administered by the Department of Health and Human Services. When disputes over allocation arise, each party must believe that in one area, resources are being wasted to address trivial health and safety problems, while in another area health and safety objectives are suffering for want of attention. For all the furor that

1 Other parts of government have also begun to embrace the concept of rational priorities, in a time of fiscal austerity; the HHS report "Healthy People 2000" (USDHHS, 1990), Oregon's decision to break from the Medicare system, and the base closings announced by the Defense Department all show a resolve to define a set of values and seek efficient pathways from here to there. 
such disputes generate, the actual side-by-side comparison of alternative uses of risk reduction resources rarely occurs, and even more rarely leads to concrete action.

Together, the increasing scrutiny paid to the total amount of national effort devoted to environmental health and safety and to how that effort is apportioned may appear to constitute a rising tide of support for such seemingly universal values as "coherence", "rationality", "efficiency", and "common-sense" in risk management. The Center regards a vigorous debate on "rationality" as long overdue, and applauds this impetus towards a more conscious and careful overall plan for environmental risk management. I am concerned, however, that the current EPA and OMB approach to risk-based planning may be insufficiently thoughtful and painstaking. To date, it appears that the vision our leaders have articulated may be insufficiently attentive to several factors, particularly: (1) scientific uncertainty in estimates of risk; (2) public perceptions of the other attributes of various hazards that color or render irrelevant the raw risk numbers; (3) the current and foreseeable technologies to ameliorate risks, whether by traditional "end-of-pipe" methods or by market, process, and product changes; and (4) the need for education, consensus, and an open process that does not thwart the outcome goal of providing more efficient and cost-effective risk reduction.

As a result of these potential deficiencies, two kinds of unfortunate consequences may result. On the one hand, the federal government may not be able to implement its reforms if they engender public skepticism and mistrust. On the other hand, some of the reforms made in the name of "rationality", if successful, may actually be premature or even counterproductive.

At present, both "too little" and "too much" success seem like plausible outcomes, because the exhortations for more rationality themselves often suffer from deficiencies of parochialism, vagueness, and negativism. Merely to agree that society cannot afford to keep dodging the hard questions about the size and priorities of its environmental programs is not enough. The experts need to offer up a positive alternative - and if that alternative is to embody "rationality" someone must begin by asking the most obvious and yet the most easily-dodged questions of all. What do we mean by "rational"? Are there multiple legitimate definitions of this term? Is this a value that the general public actually prizes, or that it can be convinced to prize? How can we assess movement towards or away from rationality in a way that takes into account both the quantitative measures of risk and the qualitative social values that color the raw statistics? How can we account for the uncertainties and controversies surrounding whatever measures we choose to compute? Finally, what strategies and technologies will enable us to move expeditiously in the direction(s) we identify as desirable?

The problem boils down to basic issues of goals and strategies. At present, society has neither explored each area sufficiently nor merged its thinking about the "why" and the "how" questions. At times, we seem to be splitting hairs over details of implementation without any clear sense of our actual destination; at other times, we appear to know where we wish to end up but are bereft of a road map to guide us on our way. Arguably, this debate will continue to emit more heat than light until society comes to grips with some basic questions involving facts and values. In order to refine our vision of how and what we can gain through "ready, aim, fire" environmental protection, the Center has developed four related projects that will form the core of our Rational Risk Reduction Program over the next three years. 


\section{Major Projects}

The core activities of the Rational Risk Reduction Program are:

(1) a careful study of the role of cost-effectiveness vis-à-vis other factors in how laypeople and "experts" gauge their support for selected environmental health regulations versus primary and secondary disease prevention programs. Many observers (see, for example, Morrall, 1986; Zeckhauser and Viscusi, 1990) and policymakers (see Table 2) have pointed out the vast disparities in the costs needed to prevent identical health endpoints (especially death from cancer) via environmental regulation or direct public health intervention. The assertion is increasingly being made that the resources devoted to (say) reducing emissions from coke ovens could save lives far more effectively if diverted to (say) expanding subsidized screening programs for breast, colorectal, and other cancers. A broader vision of the fungibility of public health resources asserts that an even better reallocation would scale back certain environmental cancer regulations in favor of basic health promotion services such as prenatal clinics or immunization programs. Few investigators, however, have attempted to assess whether our national disease prevention system is truly inefficient, or whether factors other than CPLS such as public perception of risk, concommitant ecological or other benefits, or uncertainties in the CPLS numbers themselves - can help explain the existing mix of efforts.

(2) a policy analysis of an unresolved dichotomy in risk management - the tension between reducing risks on the basis of their aggregate effects on populations versus their individualized effects on highly exposed or susceptible persons. Without recognizing that these are two very different conceptions of how to measure risk, we will never be able to gauge how large a particular risk is, let alone compare risks to each other in support of a "worst-first" policy regime. And, unless we can reconcile whether risk management should be a "civil rights" activity (HAPSG, 1989), or a public health activity (Goldstein, 1989), we will never really be able to monitor and communicate our progress towards a safer environment. Is it, for example, more important to spend money on Superfund sites (where the death toll may be low but where some individuals may face very high risks) or on mobile sources of air pollutants (which ostensibly pose smaller personal risks but larger population consequences)? Our analysis will trace the origins and history of the use of the populationincidence and individual-risk criteria in various federal programs, and examine the important empirical and ethical arguments for and against each criterion. We intend to show how inescapable is the need to consider both criteria in managing risks (and how comfortable society already is with balancing these kinds of concerns in other areas of national policy), and will develop and advocate a hybrid criterion that may help make this tension more explicit and yet more manageable.

(3) a national conference where the twin issues "should we reduce the 'worst' risks first?" and "can we reduce the worst risks first?" can be debated, and where specific guidance for the future of priority-setting can be drafted in a consensual forum. The conference to be held in November of 1992, will feature invited "point/counterpoint" presentations on several controversial questions, including: (1) are our environmental protection resources limited enough that we need to sacrifice some risk reduction efforts to expand others?; (2) is the current "adhocracy" in fact wasteful of resources and unfair in process?; (3) are the uncertainties in risk estimation manageable enough to allow for meaningful rankings?; (4) can the non-quantifiable 
aspects of risk issues (voluntariness, dread, existence values of ecosystems, etc.) be incorporated into "worst-first" ranking in a meaningful way?; and (5) are there fundamentally different paradigms for setting priorities (such as technology-driven or equitydriven systems) that are preferable to a risk-based approach? In addition, working groups will be charged with specific tasks leading to concrete end-products that may be useful as the broader policy debate continues. For example, one group may be asked to draft a charter for a possible SAB committee that would monitor the progress of comparative risk assessment and its use in planning, while another might be asked to identify knowledge gaps regarding public perceptions and values that may impede the formation of an acceptable process for setting environmental priorities.

and

(4) a detailed study of the spatial, temporal, and socioeconomic distribution of risks that affect residents of a specific U.S. city. This project has both theoretical and applied components. Center staff will develop a generic methodology utilizing geographical information systems, for integrating data on various types of environmental risks (e. g., stationary and mobile sources of air pollution, indoor radon, industrial accidents) into a "community risk profile". By then applying the methodology to a specific community, we hope to enhance the ability of state and local agencies to tailor priorities for managing risks at the local level, as well as to shed light on a growing national question affecting risk ranking: are "hot spots" of high individual risk correlated with income, race, or other relevant variables (USEPA, 1992)?

We have chosen to begin with these four activities because we see them as fundamental and highly complementary. The study of environmental health and public health initiatives will provide a window into perhaps the most basic question of all; what is society trying to purchase with its copious efforts in both areas? To the extent that our analysis, and focus group activities can explain disparities in the cost-effectiveness of measures within and across these two national enterprises, we will help policymakers understand what benefits other than longevity Americans are willing to pay for. On the other hand, these activities may reveal to decision-makers and the lay public that certain aspects of current resource allocation are in fact unresponsive to both economic efficiency and public preferences. Our policy analysis of the individual versus population risks dilemma will tackle a tough methodological hurdle affecting comparative risk management that has remained largely unaddressed. Which conception of risk prevails will largely determine how EPA and other agencies choose to ameliorate the priority risks they identify, a choice that threatens to be even more divisive than the risk ranking itself.

The conference we will convene is a critical part of the program. Actions rather than words largely accelerated the paradigm shifts that occurred at the three previous "environmental crossroads". Yet, at each of these junctures the opportunity for dialogue helped publicize new trends and mark out ideological boundaries. Finally, the attempt to detail a "community risk profile" will provide a bridge between the logical first phase of the program (defining national goals and strategies) and a second phase of work we hope to continue or pass on to others - investigation of what happens when priority-setting hits "main street" and the real work of implementation begins. Through this project (and the health focus groups in the first project), we hope to gain and transmit valuable insights into how citizens who don't necessarily "eat and sleep" with environmental issues view the array of health and social risks that affect them. 


\section{The "Early Returns"}

As of this writing (September 1991), the prospect of having national environmental priorities set via technocracy rather than "adhocracy" has engendered a surprising variety of responses among interested individuals and groups. The "early returns" run the gamut from outright hostility through celebratory advocacy, with a current of studied apathy also prominent. The easiest generalization of all to make is that many stakeholders see the "worst-first" regime as a means to a desired or dreaded end, and evaluate the broad concept only in the light of its effect on cherished issues within the environmental policy arena. For example, the cleanup of abandoned hazardous waste sites is widely touted as a prime target for "triage" under a system that does not funnel large amounts of resources towards ameliorating small health and ecological risks. Hence, some observers disgruntled with the current budgetary prominence of the Superfund program (whether for intellectual or pocketbook concerns) have embraced risk-based planning for essentially parochial reasons, while those who have economic, political, or academic stakes in this program tend to view risk-based planning as nefarious. A similar dynamic fuels the sentiments of those who discern in risk-based planning an affirmative means to pay more attention to some relatively ignored environmental problem; those advocates frustrated with the low priority historically afforded to wetlands protection, for instance, are beginning to recognize the opportunities in embracing a concept that could pay parochial dividends.

It is riskier to generalize about the determinants of stakeholders' attitude to riskbased planning as an end rather than a means. Among the academic disciplines, economists seem more receptive than life scientists; the former group may be motivated by the promise of efficiency and the latter group daunted by the difficulty of setting priorities in the face of uncertainty. ${ }^{2}$ Interestingly though, the two groups of life scientists who produced the SAB report - ecologists and health scientists - differed markedly in their enthusiasm for codifying risk priorities; the group of ecologists generated a rank-ordered list of the problems within their purview, while the health scientists could only agree on broad characterizations of problems into "high", "medium", and "low" risk groups.

A similar divergence has characterized the initial reactions of the traditional combatants in environmental politics. Business interests are beginning to rally around the priority-setting bandwagon (case in point: a major article in Fortune in May 1991 entitled "The Big Cleanup Gets it Wrong"), perhaps reflecting both a historic familiarity with strategic planning and a recognition that many of the problems the public ranks higher than the "experts" involve risks with a high "outrage factor". If these problems (e.g., Superfund sites) are de-emphasized under the new regime, the regulatory and enforcement burden on certain business sectors might lessen concommitantly.

Environmental advocacy groups, by contrast, are generally skeptical of prioritysetting; after all, they have largely helped shape the public perceptions that have caused resources to flow towards allegedly small risks. Risk-based planning also represents a

\footnotetext{
2 One of the themes of the Rational Risk Reduction Program is the influence of uncertainty in comparative risk assessment. Elsewhere (Finkel, 1990, 1991), I have written about the "myth of uncertainty" - the belief that uncertainty plagues the typical one-thing-at-a-time risk assessment (e.g., standard-setting) but can be sidestepped by conducting relative rather than absolute quantification. In fact, the uncertainties in risk comparison often compound each other rather than cancel.
} 
potential concentration of power in the hands of technical "experts", a development disconcerting to groups that typically assert the primacy of non-quantifiable moral and process values, and anathema to those groups who additionally lack the expertise to function in this new arena. However, so far the environmentalist dismay has been muted, save for a number of critiques by Congressional staff members who have championed the idea that in our pluralistic democracy the "middle-class enthusiasms" by definition have a claim to "rationality" that scientific list-making exercises do not. But the major environmental groups in the U.S. have made few plans to engage EPA or OMB on these issues, and do not seem particularly worried about the potential resource shifts nor aggrieved by characterizations that (with their help) the public has "gotten it wrong" for at least two decades. There are at least two plausible reasons for this "wait and see" approach. First, to argue publicly for any alternative vision of priority-setting implies buying in to the underlying notion that environmental control resources are in fact limited and need to be allocated more efficiently, rather than simply expanded across-theboard. Secondly, these groups (for reasons of expediency and philosophy) are accustomed to working in a reactive rather than proactive mode - they may perceive being involved in an intellectual debate as a luxury, given that they will in due time likely be able to contest the individual substantive changes that will result from applying the risk-based budgeting paradigm. Thus, the most strident opposition to a "worst-first" agenda may only manifest itself in future lobbying or litigation to prevent any erosion of attention to particular risks, that some experts may dismiss as "small".

\section{Conclusion}

Although the "early returns" indicate widely varying degrees of enthusiasm for riskbased environmental priorities, along with some apparent disinterest in the whole concept, the debate over the nature of our priorities and the process by which they will be set has always been with us and will only become more explicit in the years ahead. Table 3 displays how diverse the visions of substance and process may be, and how fundamental are the questions that considering risk-based planning could raise. Although these positions are my own caricatures rather than complete descriptions of the various visions, all of these sentiments are now being expressed as stakeholders struggle to come to grips with the semantic and ethical challenges of whether and how to reduce risks more effectively. The hierarchy in Table 3 proceeds sequentially from the least receptive to the kind of priority-setting the OMB budget document envisions (the "hard version" of riskbased planning, as contrasted to the slightly "softer" version EPA champions) (Hornstein, 1992), to the most receptive. Which view eventually prevails will speak volumes about the future of risk assessment as a tool for policymaking, about the ability of our society to face and reconcile tragic choices (Calabresi and Bobbitt, 1978), and about our will to find creative solutions that will make these choices less tragic in the future. 
Table 1:

Relative rankings of sample environmental problems

Problem

Stratospheric Ozone Depletion

Global Warming

Outdoor (Ambient) Air Pollution

Indoor Air Pollution (Including Radon)

Worker Exposure To Chemicals

Hazardous Waste

Industrial Accidents Releasing Pollution

Accidental Oil Spills
Experts

Public

Ecology \& Welfare - $\mathrm{H}$

Human Health - $\quad$ M/H

Ecology \& Welfare - $\mathbf{H}$

Human Health - $\quad$ H

Ecology \& Welfare - M

Human Health - $\quad$ H

Human Health - $\quad$ H $\quad$ H

Ecology \& Welfare - M/L

Human Health - $\quad$ M/L

Human Health - $\quad$ M/L $\quad H$

Ecology \& Welfare - L
$\mathrm{M} / \mathrm{L}$

L

$\mathrm{H}$

$\mathrm{H}$

$\mathrm{M} / \mathrm{H}$

$\mathrm{H}$

H

$\mathrm{H}$

$\mathrm{H}=$ Relatively High,

$\mathrm{M}=$ Relatively Medium,

$\mathrm{L}=$ Relatively Low.

Sources: Science Advisory Board and EPA staff; Roper Organization. 
Table 2: Risks and cost-effectiveness of selected regulations

\begin{tabular}{|c|c|c|c|c|c|}
\hline Regulation ${ }^{1}$ & $\begin{array}{r}\text { Year } \\
\text { Issued }\end{array}$ & $\begin{array}{r}\text { Health } \\
\text { or } \\
\text { Safety? }\end{array}$ & Agency & $\begin{array}{r}\text { Baseline } \\
\text { Mortality Risk } \\
\text { per Million } \\
\text { Exposed }\end{array}$ & $\begin{array}{r}\text { Cost per } \\
\text { Premature } \\
\text { Death Averted } \\
(\$ \text { Millions 1990) }\end{array}$ \\
\hline Unvented Space Heater Ban $\ldots \ldots \ldots \ldots \ldots$ & 1980 & $\mathbf{s}$ & CPSC & 1,890 & \\
\hline Aircraft Cabin Fire Protection Standard .... & 1985 & $\mathbf{S}$ & FAA & 5 & 0.1 \\
\hline Auto Passive Restraint/Seat Belt Standards & 1984 & $\mathbf{S}$ & NHTSA & 6,370 & \\
\hline 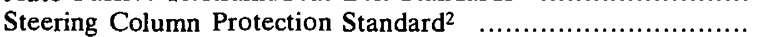 & 1967 & S & NHTSA & 385 & 0. \\
\hline Underground Construction Standards ${ }^{3} \quad \ldots$. & 1989 & $\mathbf{S}$ & OSHA-S & 38,700 & \\
\hline Trihalomethane Drinking Water Standards ... & 1979 & $\mathrm{H}$ & EPA & 420 & \\
\hline Aircraft Seat Cushion Flammability Standard & 1984 & $\mathrm{~S}$ & FAA & 11 & 0 \\
\hline Alcohol and Drug Control Standards ${ }^{3} \ldots \ldots \ldots$ & 1985 & $\mathrm{H}$ & FRA & 81 & \\
\hline Auto Fuel-System Integrity Standard & 1975 & $\mathbf{S}$ & NHTSA & 343 & 0 \\
\hline Standards for Servicing Auto Wheel Rims ${ }^{3}$. & 1984 & $\mathbf{S}$ & OSHA-S & 630 & \\
\hline Aircraft Floor Emergency Lighting Standard & 1984 & $\mathbf{S}$ & FAA & 2 & \\
\hline Concrete \& Masonry Construction Standards ${ }^{3}$. & 1988 & $\mathbf{S}$ & OSHA-S & 630 & 0 \\
\hline Crane Suspended Personnel Platform Standard ${ }^{3}$.. & 1988 & $\mathbf{S}$ & OSHA-S & 81,000 & \\
\hline Passive Restraints for Trucks \& Buses (Proposed) & 1989 & $\mathbf{S}$ & NHTSA & 6,370 & 0 \\
\hline Side-Impact Standards for Autos (Dynamic) ........ & 1990 & $\mathbf{S}$ & NHTSA & NA & 0 \\
\hline Children's Sleepwear Flammability $\mathbf{B a n}^{4} \quad \ldots$ & 1973 & $\mathbf{S}$ & CPSC & 29 & \\
\hline 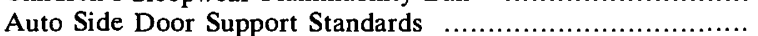 & 1970 & $\mathbf{S}$ & NHTSA & 2,520 & \\
\hline Low-Altitude Windshear Equipment \& Training Standards & 1988 & $\mathbf{S}$ & FAA & NA & \\
\hline Electrical Equipment Standards (Metal Mines) .............. & 1970 & $\mathrm{~S}$ & MSHA & NA & 1 \\
\hline Trenching and Excavation Standards ${ }^{3} \ldots \ldots \ldots \ldots \ldots \ldots \ldots$ & 1989 & $\mathbf{S}$ & OSHA-S & 14,310 & \\
\hline Traffic Alert and Collision Avoidance (TCAS) Systems ......... & 1988 & S & FAA & NA & 1. \\
\hline 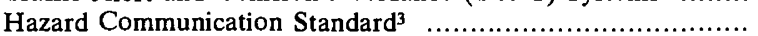 & 1983 & $\mathbf{S}$ & OSHA-S & 1,800 & \\
\hline Side-Impact Stds for Trucks, Buses and MPVs (Proposed) & 1989 & $\mathbf{S}$ & NHTSA & NA & \\
\hline Grain Dust Explosion Prevention Standards ${ }^{3}$................. & 1987 & $\mathbf{S}$ & - OSHA-S & 9,450 & 2 \\
\hline Rear Lap/Shoulder Belts for Autos . ............... & 1989 & $\mathbf{S}$ & NHTSA & NA & \\
\hline Standards for Radionuclides in Uranium Mines ${ }^{3}$. & 1984 & $\mathrm{H}$ & EPA & 6,300 & 3 \\
\hline Benzene NESHAP (Original: Fugitive Emissions) & 1984 & $\mathrm{H}$ & EPA & 1,470 & \\
\hline Ethylene Dibromide Drinking Water Standard .... & 1991 & $\mathrm{H}$ & EPA & NA & \\
\hline Benzene NESHAP (Revised: Coke By-Products) ${ }^{3}$ & 1988 & $\mathrm{H}$ & EPA & NA & \\
\hline Asbestos Occupational Exposure Limit ${ }^{3}$ & 1972 & $\mathrm{H}$ & OSHA-H & 3,015 & \\
\hline Benzene Occupational Exposure $\mathrm{Limit}^{3}$........ & 1987 & $\mathrm{H}$ & OSHA-H & 39.600 & 8 \\
\hline Electrical Equipment Standards (Coal Mines) ${ }^{3}$ & 1970 & $\mathbf{S}$ & MSHA & NA & \\
\hline Arsenic Emission Standards for Glass Plants. & 1986 & $\mathrm{H}$ & EPA & 2,660 & 13 \\
\hline Ethylene Oxide Occupational Exposure Limit ${ }^{3}$...................... & 1984 & $\mathrm{H}$ & $\mathrm{OSHA}-\mathrm{H}$ & 1,980 & 20 \\
\hline Arsenic/Copper NESHAP & 1986 & $\mathrm{H}$ & EPA & 63,000 & 23 \\
\hline Haz Waste Listing for Petroleum Refining Sludge & 1990 & $\mathrm{H}$ & EPA & 210 & 27 \\
\hline Cover/Move Uranium Mill Tailings (Inactive Sites) & 1983 & $\mathrm{H}$ & EPA & 30,100 & 31 \\
\hline Benzene NESHAP (Revised: Transfer Operations) …........ & 1990 & $\mathrm{H}$ & EPA & NA & 32 \\
\hline Cover/Move Uranium Mill Tailings (Active Sites) .............. & 1983 & $\mathrm{H}$ & EPA & 30,100 & 45 \\
\hline Acrylonitrile Occupational Exposure Limit ${ }^{3}$ & 1978 & $\mathrm{H}$ & OSHA-H & 42,300 & 51 \\
\hline 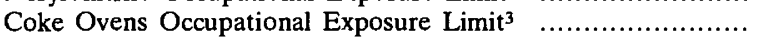 & 1976 & $\mathrm{H}$ & OSHA-H & 7,200 & 63 \\
\hline${\text { Lockout } / T_{0} \text { gout }^{3}}$ & 1989 & $\mathrm{~S}$ & OSHA-S & 4 & 70 \\
\hline Asbestos Occupational Exposure Limit $^{3}$ & 1986 & $\mathrm{H}$ & OSHA-H & 3,015 & 74 \\
\hline Arsenic Occupational Exposure Limit ${ }^{3}$. & 1978 & $\mathrm{H}$ & OSHA-H & 14,800 & 106 \\
\hline 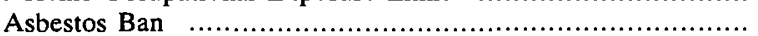 & 1989 & $\mathrm{H}$ & EPA & NA & 110 \\
\hline 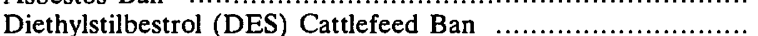 & 1979 & $\mathrm{H}$ & FDA & 22 & 124 \\
\hline 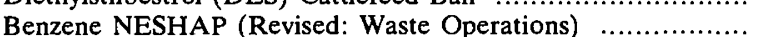 & 1990 & $\mathrm{H}$ & EPA & NA & 168 \\
\hline 1,2-Dichloropropane Drinking Water Standard ................. & 1991 & $\mathrm{H}$ & EPA & NA & 653 \\
\hline 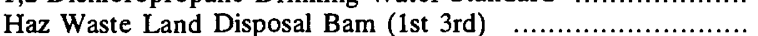 & 1988 & $\mathrm{H}$ & EPA & 2 & 4,190 \\
\hline Municipal Solid Waste Landfill Standards (Proposed) .......... & 1988 & $\mathrm{H}$ & EPA & $<1$ & 19,107 \\
\hline 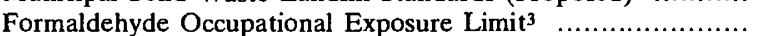 & 1987 & $\mathrm{H}$ & OSHA-H & 31 & 86,201 \\
\hline Atrazine/Alachlor Drinking Water Standard & 1991 & $\mathrm{H}$ & EPA & NA & 92,069 \\
\hline Haz Waste Listing for Wood Preserving Chemicals ................ & 1990 & $\mathrm{H}$ & EPA & $<1$ & $5,700,000$ \\
\hline
\end{tabular}

170 -year lifetime exposure assumed unless otherwise specified.

2 50-year lifetime exposure.

3 45-year lifetime exposure.

4 12-year exposure period.

$\mathrm{NA}=$ Not available.

Agency Abreviations. CPSC: Consumer Product Safety Commissions; MSHA: Mine Safety and Health Administration; EPA: Environmental Protection Agency; NHTSA: National Highway Traffic Safety Administration; FAA: Federal Aviation Administration; FRA: Federal Railroad Administration; FDA: Food and Drug Administration; OSHA-H: Occupational Safety and Health Administration, Health Standards; OSHA-S: Occupational Safety and Health Administration, Safety Standards.

Source: John F. Morrall, III, "A Review of the Record", Regulation, Vol. 10, No. 2 (1986), p. 30. Updated by the Author, et. al. 
Table 3:

\section{A Hierarchy of the "Buy-In" to Risk-Based Environmental Priorities}

- all environmental programs should be expanded - so there's no need to even think about priority-setting;

- all environmental programs should be expanded, but some more than others (subjective or parochial form of priority-setting);

- we should scale back other low-priority programs (e.g., the Space Station) before we undertake "environmental triage";

- we should be doing more, quantifying less; if we have to prioritize anything, let's rank the solutions and get on with things (this current of thought is motivated by the belief that some solutions that ameliorate small risks are cheap or even economically beneficial, and that some solutions address multiple risks);

- priority-setting based on "the worst things first" is fine, as long as quantitative risk assessment has little or nothing to do with it (democratic/consensual approach to ranking);

- if risk assessment means generating risk numbers (individual and population-based), quantifying uncertainties, and then adjusting the tentative rankings based on qualitative factors (dread, voluntariness, etc.), then it can be very useful within broad categories (health risks, ecosystem risks);

- thoughtful risk assessment, as defined above, can also yield priorities across broad categories (we can trade off disease for habitat and vice versa);

- the qualitative distinctions among risks persist because of lack of information; we should communicate the sizes of the problems better and then the public and expert rankings will more closely jibe;

- environmental protection is not a civil rights activity; we should determine the "bang for the buck" with reference to the expected size of the consequences for society as a whole and attack the worst risks first. 


\section{REFERENCES}

CALABRESI, Guido and BOBBITT, Philip, 1978. Tragic Choices (New York, W.W. Norton \& Co.).

FINKEL, Adam M., 1990. Confronting Uncertainty in Risk Management: A Guide for DecisionMakers (Washington, D. C., Resources for the Future).

FINKEL, Adam M., 1991. "Do We know Enough to Take a Risk-Based Approach?" EPA Journal 17(2), March/April 1991, p. 38.

GOLDSTEIN, Bernard D., 1989. "The Maximally Exposed Individual: An Inappropriate Basis for Public Health Decisionmaking", Environmental Forum, November/December, pp. 13-16.

Hazardous Air Pollutant Strategy Group (HAPSG). 1989. "Comments on U.S. EPA's StandardSetting Framework in the Proposed Benzene Regulations". Center for Risk Management, Resources for the Future, March 21.

HORNSTEIN, Donald T., 1992. "Reclaiming Environmental Law: A Normative Critique of Comparative Risk Analysis". Columbia Journal of Environmental Law (in press).

MORRALL, John F. III., 1986. "A Review of the Record", Regulation, vol. 10, pp. 25-44.

U.S. Department of Health and Human Services, 1990. Healty People 2000: National Health Promotion and Disease Prevention Objectives (Washington, D.C., DHSS).

U.S. Environmental Protection Agency, Office of Policy, Planning, and Evaluation, 1992. Environmental Equity: Reducing Risk for All Communities (Washington, D.C., EPA, \# 230-DR-92-002).

ZECKHAUSER, Richard J. and VISCUSI, W. Kip, 1990. "Risk Within Reason", Science, vol. 238, pp. 559-564. 